\title{
Laser Induced Breakdown Spectroscopy for Heavy Metal Detection in a Sand Matrix
}

\author{
Anna P. M. Michel ${ }^{\mathrm{a}, \mathrm{b}}$, Frederick Sonnichsen ${ }^{\mathrm{a}}$ \\ ${ }^{a}$ Department of Applied Ocean Physics and Engineering, Woods Hole Oceanographic \\ Institution, 266 Woods Hole Road, Woods Hole, MA 02543 \\ ${ }^{b}$ Corresponding Author: amichel@whoi.edu
}

\begin{abstract}
Sediments in many locations, including harbors and coastal areas, can become contaminated and polluted, for example, from anthropogenic inputs, shipping, human activities, and poor waste management. Sampling followed by laboratory analysis has been the traditional methodology for such analysis. In order to develop rapid methodologies for field analysis of sediment samples, especially for metals analyses, we look to Laser Induced Breakdown Spectroscopy as an option. Here through laboratory experiments, we demonstrate that dry sand samples can be rapidly analyzed for the detection of the heavy metals chromium, zinc, lead, and copper. We also demonstrate that cadmium and nickel are detectable in sand matrices at high concentrations.
\end{abstract}

Keywords: Laser-induced breakdown spectroscopy; Spectrochemical analysis; Sediment Analysis; Metals

\section{Introduction}

Pollutants from shipping, mining, industrial processes, and waste inputs can reach ocean and river sediments. Many harbors, coastal environments, rivers, and estuarine environments have been negatively impacted by such inputs. When contaminated sediments result, negative impacts can been seen on fisheries, shellfishing, and benthic communities in addition to playing a role in human health and local communities. Sediments accumulate and sometimes concentrate often toxic metals due to the influx of contaminants from anthropogenic sources. Shellfish can accumulate significant levels of metals resulting in a health risk if consumed, for example, by sensitive 
populations such as pregnant women. Closings to shellfishing and consumption advisories may also result. Impact from the contaminated sediment is seen in fisheries, shellfishing, benthic communities, water quality, and human health.

Identifying the presence of heavy metals in sediments is of key importance due to their negative environmental, ecological, and human health impacts (e.g. [1-3]). Areas with elevated levels must be identified as it is critical for remediation decision making and for monitoring of remediation efforts. It is essential to analyze sediments to determine the presence of such contaminants and heavy metals. Such monitoring efforts can be time intensive and spatially limited. It is often necessary to use a boat and grab sampler or corer to retrieve the samples, process the collected samples, then finally make laboratory-based measurements (e.g. plasma-optical emission spectroscopy and inductively-coupled plasma mass spectrometry). To decrease analysis time and spatial resolution, we look towards the ability to rapidly analyze samples shipboard, in situ, and in the field.

Laser induced breakdown spectroscopy (LIBS) is a type of atomic emission spectroscopy that can provide rapid, simultaneous multi-element analysis. Elemental analysis of solid, liquid, and gas samples is achievable with LIBS. These characteristics make LIBS an ideal technique for field-going measurements and we look to it as an option for in situ or shipboard analysis of ocean and river sediments. The LIBS technique has applicability to geological, biological, and chemical samples (e.g. [4-12]).

Due to the diverse nature of such samples, LIBS shows promise to a range of applications in marine and riverine environments. Several studies have looked at the feasibility of underwater LIBS, primarily for applications such as vent fluids, archaeology, and solids analysis [13-21]. Groups have demonstrated LIBS for analysis of soil samples and sediments (including heavy metals analysis) [22-29], for marine sediment applications [30, 31], for metallic targets underwater [32], and recently an oceanographic sensor was developed and deployed [33-35], yet, to date no commercial system exists for in situ sensing of marine and riverine sediments or shipboard analysis of such sediments.

Here we target a set of heavy metals [cadmium $(\mathrm{Cd})$, chromium $(\mathrm{Cr})$, nickel $(\mathrm{Ni})$, zinc $(\mathrm{Zn})$, lead $(\mathrm{Pb})$, and copper $(\mathrm{Cu})$ ] to investigate the feasibility of detecting them in sand matrices using LIBS. We focus on these analytes due to their detrimental impacts on the environment and their subsequent impacts on human health. Emission lines in the $200-600 \mathrm{~nm}$ range 
are targeted due to their line strengths in the ultraviolet - visible (UV-VIS) spectral region [36]. The $200 \mathrm{~nm}$ to $400 \mathrm{~nm}$ region is of critical importance due to the abundance of spectral lines in the ultraviolet region for many of the targeted metals. Here we focus on detection of these metals in dry samples as the first step towards a field-deployable sediment analyzer.

\section{Materials and Methods}

\subsection{Sample Preparation}

Artificial dry sediment samples were prepared for these laboratory experiments to simulate samples found in polluted waterways. Commerciallyavailable sand was spiked with varying amounts of dry compounds to produce samples of varying concentrations for analyses. The compounds used were: $\mathrm{CdCO}_{3}(\mathrm{Cd}) ; \mathrm{ZnCrO}_{4}(\mathrm{Cr}) ; \mathrm{CuCO}_{3}(\mathrm{Cu}) ; \mathrm{PbCO}_{3}(\mathrm{~Pb}) ; \mathrm{NiCO}_{3}(\mathrm{Ni})$; and $\mathrm{ZnCO}_{3}(\mathrm{Zn})$. After spiking the sand with the targeted compound, the samples were mixed for 60 seconds using a vortex mixer in an effort to create homogenous samples. Samples were placed in closed acrylic sample chambers with sapphire windows or X-ray fluorescence (XRF) sample cups with mylar covers.

\subsection{LIBS Experimental Set-up}

Two LIBS laboratory setups were utilized and are shown in Figures 1 and 2. A Big Sky CFR-200 Nd:YAG laser operated at $1064 \mathrm{~nm}$ (9 ns pulses) with a $5 \mathrm{~Hz}$ repetition rate was used for plasma formation. Laser pulse energies used ranged from $15 \mathrm{~mJ}$ to $50 \mathrm{~mJ}$ (details shown in Table 1).

Figure 1 was used for $\mathrm{Zn}$ and $\mathrm{Pb}$ analysis and Figure 2 was used for $\mathrm{Cu}$, $\mathrm{Cd}, \mathrm{Cr}$, and $\mathrm{Ni}$ analysis. The plasma was formed on the sediment surface by focusing using a $50 \mathrm{~mm}$ focal length lens for $\mathrm{Cu}, \mathrm{Cd}, \mathrm{Cr}$, and $\mathrm{Ni}$ or a $35 \mathrm{~mm}$ focal length lens for $\mathrm{Zn}$ and $\mathrm{Pb}$.

For $\mathrm{Zn}$ and $\mathrm{Pb}$, a collinear set up was used, thus, a dichroic mirror (Thorlabs DMSP805) was used for reflecting the laser light towards the sediment while passing the plasma return signal. This method, with its focusing optics, is capable of collecting a strong signal however the fused silica glasses found in readily available dichroic mirrors begin to attenuate the signal below about $400 \mathrm{~nm}$. Similarly the BK-7 lenses attenuate over $50 \%$ of the signal below $300 \mathrm{~nm}$. 
Table 1: LIBS Experimental Parameters

\begin{tabular}{|c|c|c|c|c|c|}
\hline Element & $\begin{array}{c}\text { Laser Pulse } \\
\text { Energy }\end{array}$ & $\begin{array}{l}\text { Gate } \\
\text { Delay }\end{array}$ & $\begin{array}{c}\text { Gate } \\
\text { Width }\end{array}$ & $\begin{array}{c}\text { On Chip } \\
\text { Accumulations }\end{array}$ & Gain \\
\hline Cadmium & $\begin{array}{c}20 \mathrm{~mJ}(50 \mathrm{ppm}, 500 \mathrm{ppm}, 1000 \mathrm{ppm}) \\
30 \mathrm{~mJ}(250 \mathrm{ppm}) \\
40 \mathrm{~mJ}(100 \mathrm{ppm})\end{array}$ & $563 \mathrm{~nm}$ & $3000 \mathrm{~ns}$ & 5 & 3600 \\
\hline Chromium & $30 \mathrm{~mJ}$ & $563 \mathrm{~ns}$ & $3000 \mathrm{~ns}$ & 5 & 3600 \\
\hline Copper & $\begin{array}{l}30 \mathrm{~mJ}(25 \text { and } 50 \mathrm{ppm}) \\
15 \mathrm{~mJ}(250 \mathrm{ppm}) \\
10 \mathrm{~mJ}(500 \mathrm{ppm}) \\
50 \mathrm{~mJ}(1060 \mathrm{ppm})\end{array}$ & $563 \mathrm{~ns}$ & $3000 \mathrm{~ns}$ & 5 & 3600 \\
\hline Lead & $30 \mathrm{~mJ}$ & $313 \mathrm{~ns}$ & $3000 \mathrm{~ns}$ & 50 & 3000 \\
\hline Nickel & $\begin{array}{c}50 \mathrm{~mJ}(25 \mathrm{ppm}, 500 \mathrm{ppm}) \\
30 \mathrm{~mJ}(50 \mathrm{ppm}) \\
20 \mathrm{~mJ}(1000 \mathrm{ppm})\end{array}$ & $563 \mathrm{~ns}$ & $3000 \mathrm{~ns}$ & 5 & 3600 \\
\hline Zinc & $30 \mathrm{~mJ}$ & $313 \mathrm{~ns}$ & $1500 \mathrm{~ns}$ & 50 & 3000 \\
\hline
\end{tabular}

Plasma emission was collected by focusing the light onto a fiber optic connected to an Echelle spectrometer (LLA Echelle ESA 3000). The spectrometer has a spectral coverage of 200 to $780 \mathrm{~nm}$ with a spectral resolution of $10-50 \mathrm{pm}$. A $40 \mathrm{~mm}$ focal point lens was used to focus light onto the fiber optic for $\mathrm{Pb}$ and $\mathrm{Zn}$ experiments to achieve the highest possible fluence into the spectrometer. However, this final focusing lens was not used for the $\mathrm{Cd}$, $\mathrm{Cr}, \mathrm{Cu}$, and $\mathrm{Ni}$ experiments and instead a direct fiber approach was used in an effort to maximize plasma signal collected. In the direct fiber approach, the fiber was directly placed within $1 \mathrm{~cm}$ of the plasma.

An automated rotation stage (Thorlabs CR1-Z7) was used to continuously turn the samples to avoid resampling in a crater formed from a previous shot.

A timing box (Berkeley Nucleonics Corporation Model 565) was utilized to precisely control the timing between the laser pulse and turn-on of the spectrometer (gate delay). The integration time (gate width) was controlled by the spectrometer. Each spectrum was made from multiple on-chip accumulations and multiple spectra $(5-10)$ and the gain was set to maximize signal without saturating the ICCD. The LIBS parameters used are detailed in Table 1. The alteration of the LIBS parameters (gate width, gate delay, gain, pulse energy) for the different samples was necessary for obtaining the best spectra (improved signal:noise). 


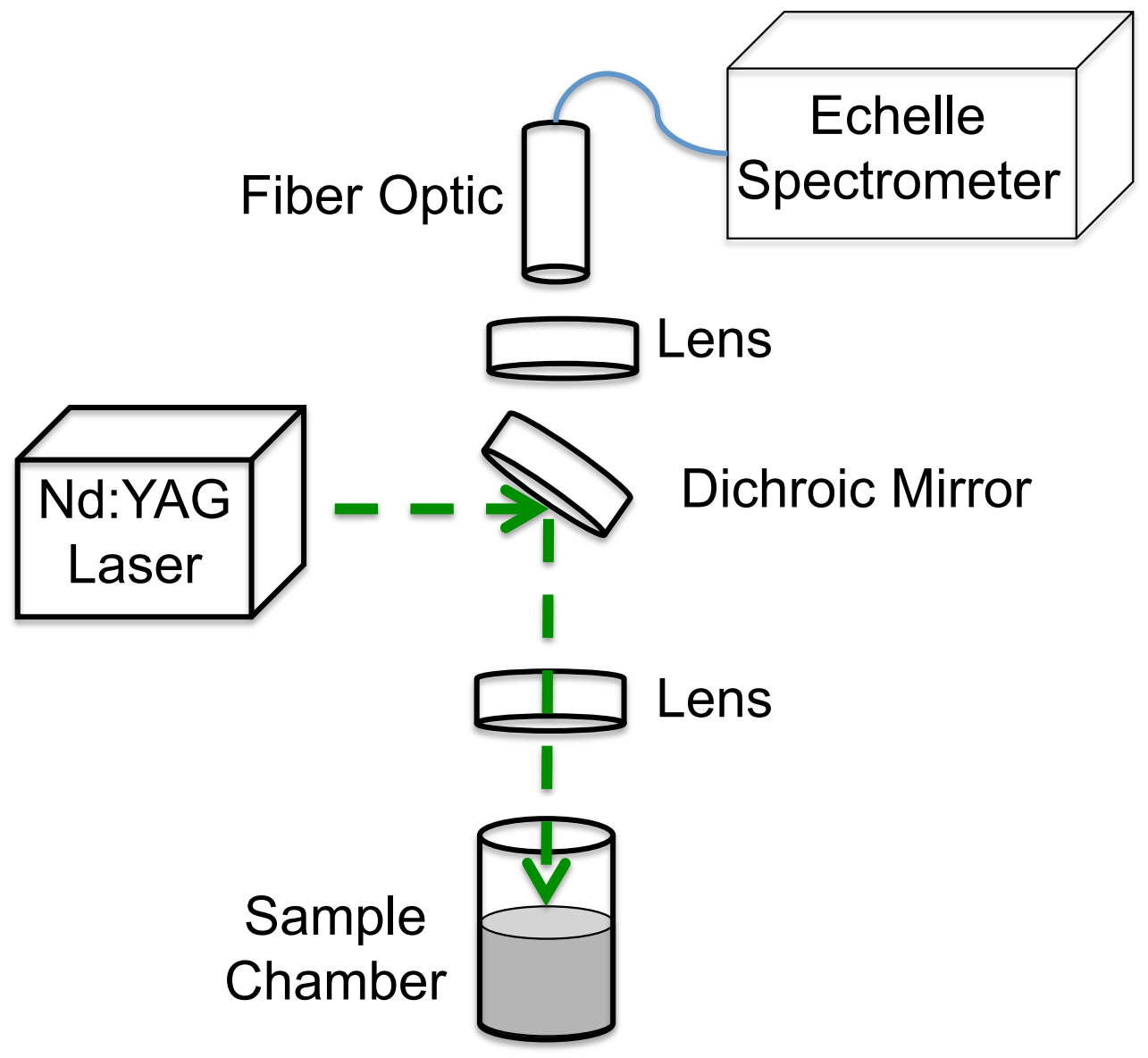

Figure 1: Schematic of the Echelle spectrometer-based system using for the detection of zinc and lead. A dichroic mirror was used for reflecting the laser light towards the sediment while passing the plasma return signal. A $35 \mathrm{~mm}$ lens was utilized for focusing the laser light onto the sediment sample in the sampling chamber to form the plasma. A $40 \mathrm{~mm}$ focusing lens was used to focus light onto the fiber optic to achieve the highest possible fluence into the spectrometer. 


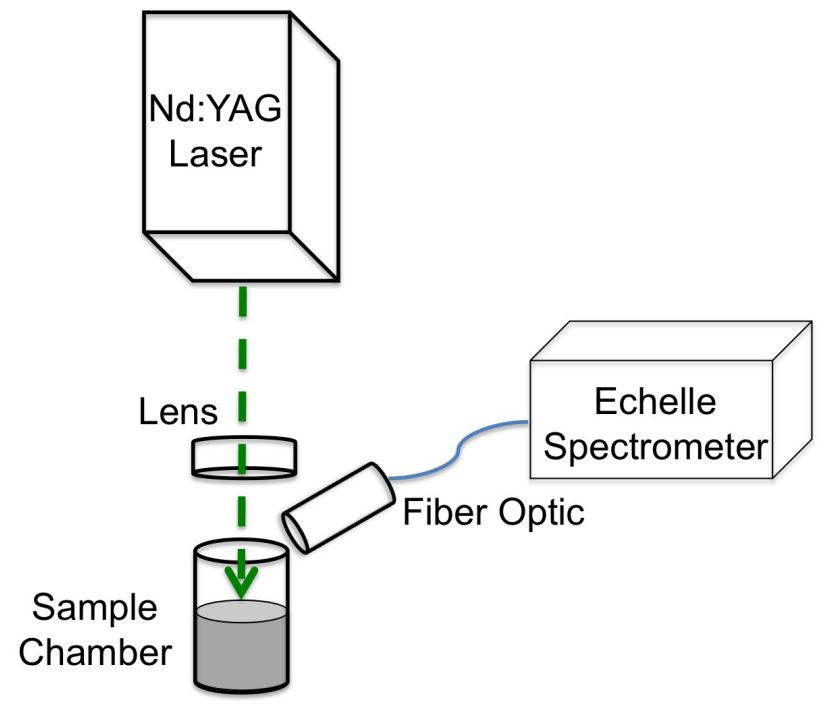

Figure 2: Schematic of the Echelle spectrometer-based system using the direct fiber approach for copper, cadmium, chromium, and nickel. A $50 \mathrm{~mm}$ focal length lens was utilized for focusing the laser light onto the sediment sample in the sample chamber. 
Due to issues with saturation of the detector, continuum radiation, and the overall goal of determining if this methodology can be used for sediments, laser energy levels were also varied as needed (Table 1). It was necessary to alter the laser energy between various concentration levels in order to obtain unsaturated peaks that fell within the limits of the spectrometer maximum. If the alteration of the LIBS parameters led to saturation of the spectrometer's ICCD, spectra were discarded.

\subsection{LIBS Data Processing}

Peak intensity was used as a representation of the analyte concentration contained in the sample. In order to account for spectrometer and laser parameter alterations to maintain useful spectra, shot-to-shot variability characteristic of the random nature of plasma formation, and sample variability (heterogeneity, amorphousness), each spectral peak targeted was normalized by a peak within the same spectrum from an element that is a component of the sand. The use of a reference peak has been utilized by many groups (e.g. $[10,37,38])$. The reference peak was selected from the elemental composition of the sand as we treat these to be at a constant concentration within the sand. The ratio of the two spectral peaks, one for the element of interest and one as a reference peak, was calculated. Calcium and aluminum are used as reference peaks as they are both readily detectable and have peaks that do not interfere with the target analytes. Both the sample and reference wavelengths are shown in Table 2 . The reference peaks used were: $393 \mathrm{~nm}$ Ca for lead and copper; $422 \mathrm{~nm}$ Ca for zinc; $308 \mathrm{~nm} \mathrm{Al}$ for chromium and cadmium; and $403 \mathrm{~nm}$ Al peak for nickel. The utilization of the spectral peak ratio allowed us to account for the changes in experimental conditions that were needed to maximize the signal-to-noise ratio.

Peak intensities of LIBS spectra display an extreme value statistical distribution [39]. Thus instead of simply averaging multiple spectra taken of a sample, here the location parameter $(\mu)$ and the scale parameter $(\sigma)$ are determined. The location parameter is analogous to the mean and the scale parameter is analogous to the standard deviation for the Gaussian distribution.

\subsection{X-ray Fluorescence (XRF)}

A handheld XRF analyzer (XMET 7500, Oxford Instruments) was utilized for secondary sample analysis on the samples. XRF analysis time for 
Table 2: Table showing the targeted wavelengths for both the targeted analyses $(\mathrm{Cd}, \mathrm{Cr}$, $\mathrm{Cu}, \mathrm{Pb}, \mathrm{Ni}$, and $\mathrm{Zn}$ and the reference analytes (Al and $\mathrm{Ca}$ ).

\begin{tabular}{|l|l|}
\hline Element & Wavelength(s) (nm) \\
\hline Aluminum $(\mathrm{Al})$ & 308 (reference peak) \\
\hline Cadmium $(\mathrm{Cd})$ & 480 \\
\hline Calcium $(\mathrm{Ca})$ & 393,422 (reference peaks) \\
\hline Chromium $(\mathrm{Cr})$ & 425 \\
\hline Copper $(\mathrm{Cu})$ & 325 \\
\hline Lead $(\mathrm{Pb})$ & 406 \\
\hline Nickel $(\mathrm{Ni})$ & 342 \\
\hline Zinc $(\mathrm{Zn})$ & $468,472,481$ \\
\hline
\end{tabular}

each sample was $300 \mathrm{~s}$. Here, XRF results are reported as the ratio of two elements, where the value of each element measured is in weight $\%$.

\section{Results}

\subsection{Zinc}

Using a low laser pulse energy $(30 \mathrm{~mJ})$, Zinc was easily detectable in the samples with three distinct peaks at $468 \mathrm{~nm}, 472 \mathrm{~nm}$, and $481 \mathrm{~nm}$ present. Although the intensities measured at $481 \mathrm{~nm}$ were significantly higher than at $472 \mathrm{~nm}$, the $472 \mathrm{~nm}$ peak is used as spectrometer saturation occurs easily with the $481 \mathrm{~nm}$ peak. As Zn concentration increases, a corresponding linear increase in peak intensity ratio was measured (Figure 3a). Above 600 ppm, the calibration curve becomes non-linear due to the high concentration of zinc with self-absorption being exhibited. As the ratio of $\mathrm{Zn}$ to $\mathrm{Ca}$ as measured by XRF increased, we also saw a corresponding linear increase in the ratio of $\mathrm{Zn}$ to Ca measured by LIBS. This effect is seen in Figure $3 \mathrm{~b}$ where the ratio measured by XRF is compared directly to the ratio measured by LIBS. Zinc in dry sand is detectable down to a concentration of $25 \mathrm{ppm}$ (spectrum shown in offset in Figure 3a); with concentrations above 600 ppm not quantifiable.

\subsection{Lead}

Lead detection was achievable with a low laser pulse energy $(30 \mathrm{~mJ})$. As the concentration of lead was increased, a linear increase in the $\mathrm{Pb} / \mathrm{Ca}$ ratio 
was seen (Figure 4a) until the concentration was above 600 ppm, when the high concentration of lead resulted in a non-linear deviation attributable to self-absorption. Using LIBS, lead in the sand matrix was detectable at a 50 ppm concentration (Figure 4a). When comparing the ratio of the concentration of lead to calcium measured by LIBS with that measured by XRF, we see a corresponding increase in intensities with a higher $\mathrm{Pb} / \mathrm{Ca}$ ratio (Figure $4 b)$.

\subsection{Chromium}

Chromium was detectable with a low laser pulse energy of $30 \mathrm{~mJ}$. As the $\mathrm{Cr}$ concentration increased, a corresponding linear increase in the LIBS intensity ratio of $\mathrm{Cr} / \mathrm{Al}$ was seen (Figure 5a). Chromium was overall detectable at 25 ppm using LIBS (Figure 5a). Non-linearity appears at the high concentrations (500 ppm) again attributable to self-absorption. Low ratios of LIBS ratios $\mathrm{Cr} / \mathrm{Al}$ are difficult to distinguish with XRF (Figure 5b).

\subsection{Cadmium}

Although there was an increase in the $\mathrm{Cd} / \mathrm{Al}$ peak intensity ratio with an increase the $\mathrm{Cd}$ concentration, it is only at the higher concentrations (250 $\mathrm{ppm}$ ) that $\mathrm{Cd}$ is detectable (Figures $6 \mathrm{a}$ and $6 \mathrm{~b}$ ). Cadmium was difficult to detect in the spiked sand samples. A spectrum of this lowest detection level (250 ppm) is shown offset in Figure 6a.

\subsection{Copper}

For copper, although small peaks were detectable at concentrations of 50 ppm and $100 \mathrm{ppm}$, it is not until a concentration of $250 \mathrm{ppm}$ where strong signals appear (Figure $7 \mathrm{a}$ and $7 \mathrm{~b}$ ) and similarly the LIBS peak intensities remained relatively low as the ratio of $\mathrm{Cu} / \mathrm{Ca}$ was increased (Figure 7a).

\subsection{Nickel}

Nickel was difficult to detect in sand using LIBS and concentrations of $500 \mathrm{ppm}$ or greater were needed for detection. The non-linearity in the curve suggests self-absorption may be occurring at high concentration. Figure 8a shows that as concentration increases, the ratio of $\mathrm{Ni} / \mathrm{Al}$ increases but that it is not until higher concentrations of $\mathrm{Ni}$ that a signal starts to emerge. Similarly, using XRF, we see that the concentration ratio of $\mathrm{Ni} / \mathrm{Al}$ must be sufficiently high $(\sim 0.5)$ for the LIBS signal to be detectable (Figure $8 \mathrm{~b}$ ). 


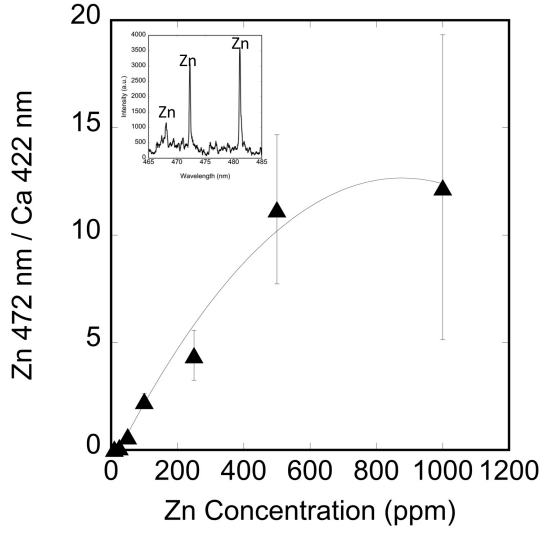

(a) The ratio of $\mathrm{Zn}(472 \mathrm{~nm})$ to $\mathrm{Ca}(422 \mathrm{~nm})$ peak intensities measured by LIBS versus the $\mathrm{Zn}$ concentration (ppm). Inset spectrum shows $25 \mathrm{ppm}$ Zn measured by LIBS. This spectrum is shown smoothed with a moving average filter (20 data point smoothing).

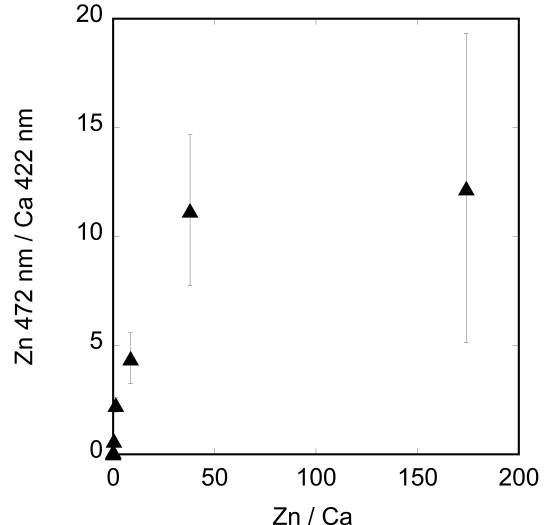

(b) The ratio of $\mathrm{Zn}(472 \mathrm{~nm})$ to $\mathrm{Ca}(422 \mathrm{~nm})$ peak intensities measured by LIBS to the $\mathrm{Zn} / \mathrm{Ca}$ concentration ratio measured by XRF.

Figure 3: Analysis of zinc in a sand matrix using LIBS and XRF. 


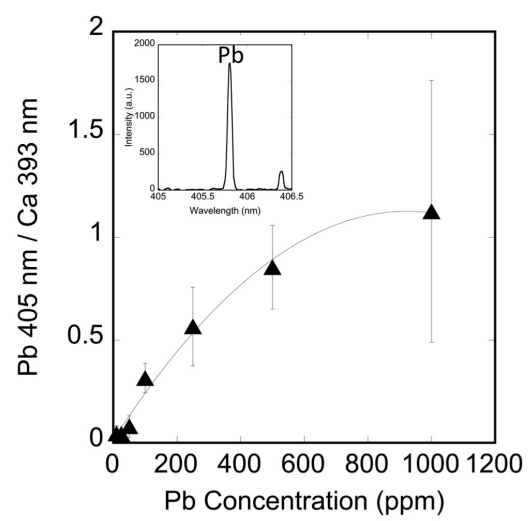

(a) The ratio of $\mathrm{Pb}(405 \mathrm{~nm})$ to $\mathrm{Ca}(393 \mathrm{~nm})$ peak intensities measured by LIBS versus the $\mathrm{Pb}$ concentration (ppm). Inset shows spectrum shows $50 \mathrm{ppm}$ lead measured by LIBS. This spectrum is shown smoothed with a moving average filter (5 data point smoothing)

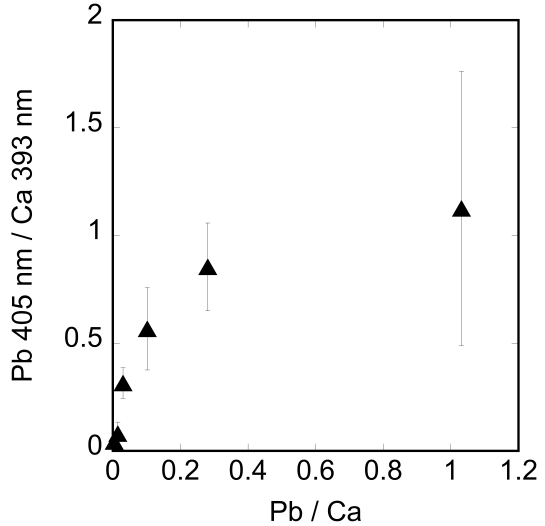

(b) The ratio of $\mathrm{Pb}(405 \mathrm{~nm})$ to $\mathrm{Ca}(393 \mathrm{~nm})$ peak intensities measured by LIBS to the $\mathrm{Pb} / \mathrm{Ca}$ concentration ratio measured by $\mathrm{XRF}$.

Figure 4: Analysis of lead in a sand matrix using LIBS and XRF. 


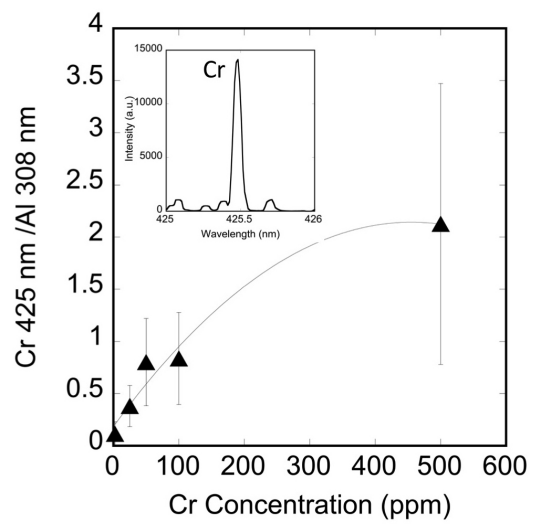

(a) The ratio of $\mathrm{Cr}(425 \mathrm{~nm})$ to $\mathrm{Al}(308 \mathrm{~nm})$ peak intensities measured by LIBS versus the $\mathrm{Cr}$ concentration (ppm). Inset spectrum shows $25 \mathrm{ppm}$ Cr measured by LIBS. This spectrum is shown smoothed with a moving average filter (5 data point smoothing).

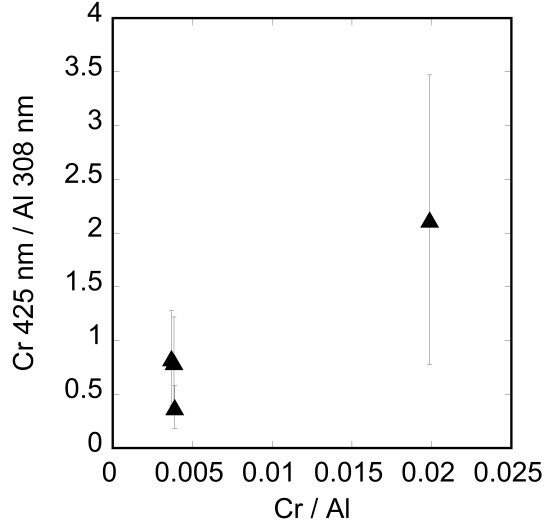

(b) The ratio of $\mathrm{Cr}(425 \mathrm{~nm})$ to $\mathrm{Al}(308 \mathrm{~nm})$ peak intensities measured by LIBS versus the $\mathrm{Cr} / \mathrm{Ca}$ concentration ratio measured by XRF.

Figure 5: Analysis of chromium in a sand matrix using LIBS and XRF. 


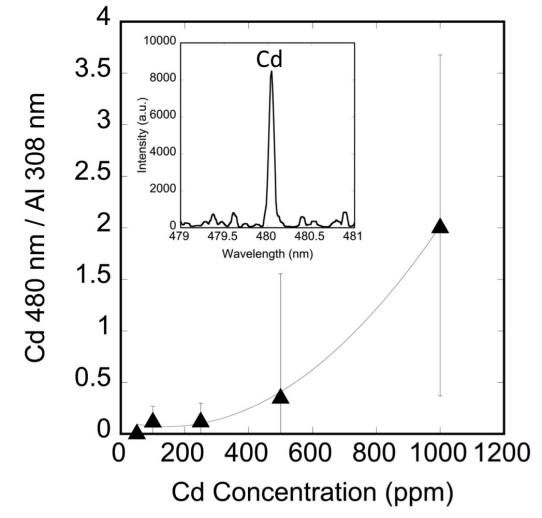

(a) The ratio of $\mathrm{Cd}(480 \mathrm{~nm})$ to $\mathrm{Al}(308 \mathrm{~nm})$ peak intensities measured by LIBS versus the $\mathrm{Cd}$ concentration (ppm). Inset spectrum shows 250 ppm Cd measured by LIBS. This spectrum is shown smoothed with a moving average filter (5 data point smoothing).

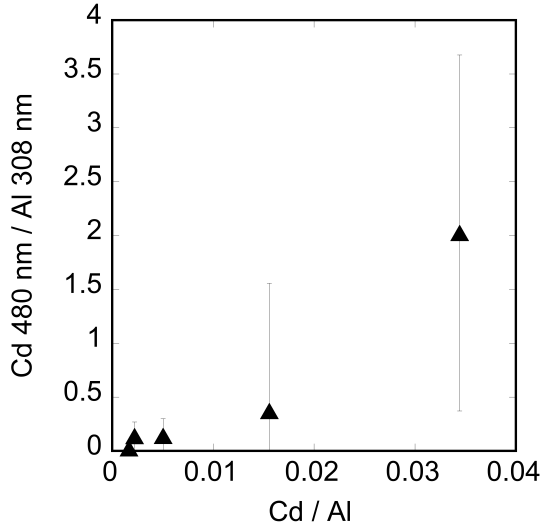

(b) The ratio of $\mathrm{Cd}(480 \mathrm{~nm})$ to $\mathrm{Al}(308 \mathrm{~nm})$ peak intensities measured by LIBS versus the $\mathrm{Cd} / \mathrm{Ca}$ concentration ratio measured by XRF.

Figure 6: Analysis of cadmium in a sand matrix using LIBS and XRF. 


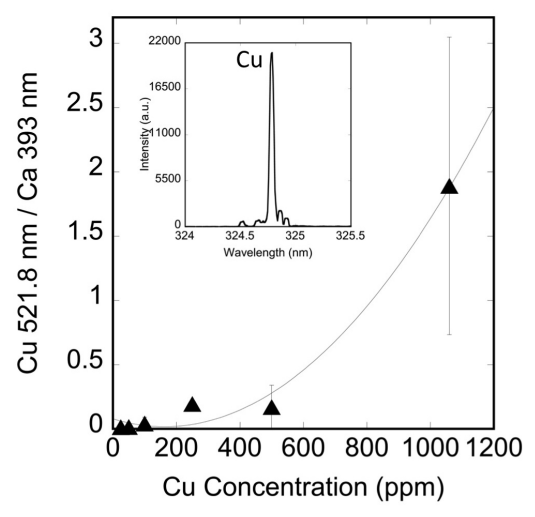

(a) The ratio of $\mathrm{Cu}(325 \mathrm{~nm})$ to $\mathrm{Ca}(393 \mathrm{~nm})$ peak intensities measured by LIBS versus the $\mathrm{Cu}$ concentration (ppm). Inset spectrum of $250 \mathrm{ppm} \mathrm{Cu}$ measured by LIBS. This spectrum is shown smoothed with a moving average filter ( 5 data point smoothing).

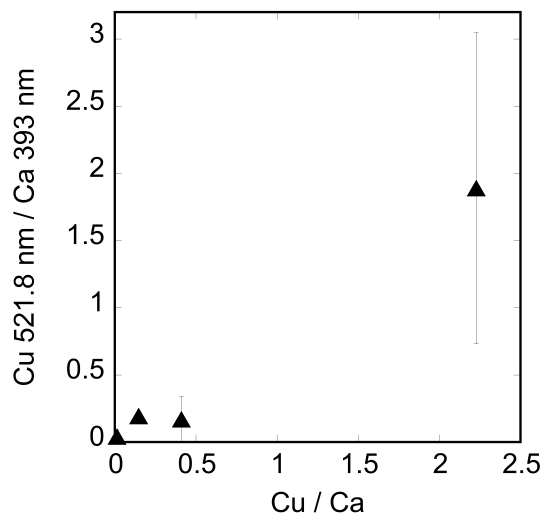

(b) The ratio of $\mathrm{Cu}(325 \mathrm{~nm})$ to $\mathrm{Ca}(393 \mathrm{~nm})$ peak intensities measured by LIBS versus the $\mathrm{Cu} / \mathrm{Ca}$ concentration ratio measured by XRF.

Figure 7: Analysis of copper in a sand matrix using LIBS and XRF. 


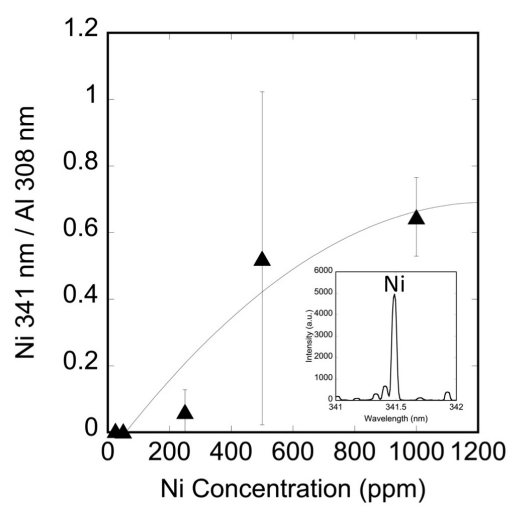

(a) The ratio of $\mathrm{Ni}(341.5 \mathrm{~nm})$ to $\mathrm{Al}(403 \mathrm{~nm})$ peak intensities measured by LIBS versus the $\mathrm{Ni}$ concentration (ppm). Inset spectrum of $500 \mathrm{ppm} \mathrm{Ni}$ measured by LIBS. This spectrum is shown smoothed with a moving average filter ( 5 data point smoothing).

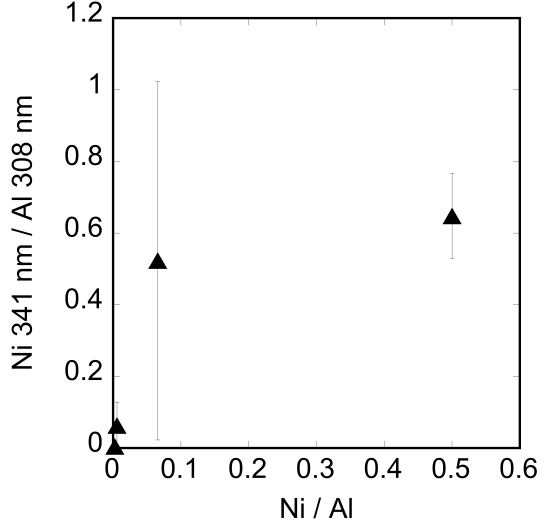

(b) The ratio of $\mathrm{Ni}(341.5 \mathrm{~nm})$ to $\mathrm{Al}(403 \mathrm{~nm})$ peak intensities measured by LIBS versus the $\mathrm{Ni} / \mathrm{Al}$ concentration ratio measured by XRF.

Figure 8: Analysis of nickel in a sand matrix using LIBS and XRF. 


\section{Discussion}

Several challenges must be recognized for sediment analysis. Sediment targets are disturbed by the thermo-mechanical energy of the laser which leads to particulate sediment plumes that obscure the light path. This creates a limitation to the number of sample shots that can be taken as each laser shot will disturb the sediment. It is therefore essential to optimize the optical system to achieve highly sensitive and highly precise measurements of sediments with limited plasma formation cycles. Since sediment is highly amorphous and heterogeneous, changes in the focal point can also be seen, thus the shot-to-shot variability will be high. The large error bars on the high concentrations can be attributed to these issues and the plasma variability. Overall, a relatively low laser energy $(\leq 50 \mathrm{~mJ})$ was used for the detection of the heavy metals. The use of low laser energy is important for field applications as it opens up the possibility of using smaller lasers with less wall plug power needs.

Significant variability was seen between spectra, most likely attributable to focal point changes as the surface is non-uniform and to the heterogeneity of the samples. The laser effectively drills through the layer of sediment forming a crater. The physical variability associated with the crater depth impacts the measurement due to a change in focal point. Focal point changes affect not only the quality of the laser induced plasma generated but also the light focused into the spectrometer. Sample heterogeneity most likely still exists despite best efforts to create homogeneous samples, thus significant shot-to-shot variability may occur due to the variability of the sample itself. This is not unrealistic in the case of real sediment samples. Plasma formation itself is variable and contributes to the changes between spectra.

The calibration curves presented are generally linear in the lower concentration regions; yet, become non-linear with higher concentrations. The non-linear responses is often due to self-absorption occurring at the higher concentrations [40]. When self-absorption occurs, a decrease in peak height is exhibited along with line width broadening. The calibration curve shifts from the linear regime to a flattening regime from the saturation of the spectral line. The non-linearity we observed due to self-absorption of the lines by the plasma can be present when the actual laser-induced plasmas are formed under atmospheric pressure conditions [41]. The non-linearity can also be impacted when intense lines are used. Such intense lines are selected due to the need to often reach lower detection levels for environmental samples 
Table 3: Table comparing concentrations detectable in spiked sand samples with those found over time at New Bedford Harbor. The New Bedford Harbor data is taken from Nelson and Bergen (2012) [42].

\begin{tabular}{|c|c|c|}
\hline Element & New Bedford Harbor [ppm] & LIBS Analysis [ppm] \\
\hline $\mathrm{Cd}$ & $0.2-65$ & 250 \\
\hline $\mathrm{Cr}$ & $19-428$ & 25 \\
\hline $\mathrm{Cu}$ & $19-841$ & 250 \\
\hline $\mathrm{Ni}$ & $5-65$ & 500 \\
\hline $\mathrm{Pb}$ & $18-346$ & 50 \\
\hline $\mathrm{Zn}$ & $42-850$ & 25 \\
\hline
\end{tabular}

[41]. Therefore consideration must be given to the choice of spectral lines, understanding that a trade-off exists between saturation of the spectral line and targeting low detection limits.

New Bedford Harbor in Massachusetts (U.S.A.) was designated in 1983 as a marine Superfund site [42]. The sediment in this harbor has become polluted over many years with high concentrations of PCBs and heavy metals. This harbor is used as a point of comparison for the detection levels achieved here (Table 3).

From Table 3, it is clear that our limits of detection are within the range of concentrations for $\mathrm{Cr}, \mathrm{Zn}, \mathrm{Pb}$, and $\mathrm{Cu}$ previously reported for New Bedford Harbor. For $\mathrm{Cd}$ and $\mathrm{Ni}$, our best detection levels were higher than the levels found in the harbor and thus LIBS may not be the best path forward for detection of these elements or other conditions need to be considered further (e.g. higher pulse energies, double pulse LIBS).

Although significant variability exists due to the heterogeneity of the samples and their amorphous nature, these studies, reveal that the LIBS technique is capable of heavy metal detection in sediments. To date we have shown detection of zinc, cadmium, lead, copper, chromium, and nickel in samples in a sand matrix. We show the viability of using LIBS as an analytical technique for sediment analysis and more specifically of polluted sediments. Although we have demonstrated the ability to rapidly detect several heavy metals in dry sediment samples, our future investigations will focus on lowering the limits of detection, expanding target elements, and on the ability to analyze both wet sediment samples and submerged samples. 
Our efforts have used relatively low laser pulse energies, paving the way for compact field-going systems. These efforts will allow us to move towards field going systems that can identify heavy metal pollutants rapidly and in situ, identifying areas for further chemical analysis and possible remediation efforts. The ability to measure chemicals in sediment or sand samples, has broad applicability in such fields as ocean and riverine sciences and mining. Higher pulse energies could be explored, but blasting the dry sediments with higher pulse energies will create bigger craters and possibly more focal point variability thus more variability overall.

\section{Acknowledgements}

This work is supported by funding from the National Science Foundation (OCE-RIG: 1322704) and the Woods Hole Oceanographic Institution by The Penzance Endowed Fund in Support of Assistant Scientists and The Reuben F. and Elizabeth B. Richards Endowed Fund in Support of Scientific Staff. The authors thank A. Chave (WHOI) for the use of laboratory LIBS equipment. 


\section{References}

[1] P.B. Tchounwou, C.G. Yedjou, A.K. Patlolla, and D.J. Sutton. Heavy metal toxicity and the environment. In Molecular, clinical and environmental toxicology, pages 133-164. Springer, 2012.

[2] R. Yu, X. Yuan, Y. Zhao, G. Hu, and X. Tu. Heavy metal pollution in intertidal sediments from Quanzhou Bay, China. Journal of Environmental Sciences, 20(6):664-669, 2008.

[3] M. Maanan, M. Saddik, M. Maanan, M. Chaibi, O. Assobhei, and B. Zourarah. Environmental and ecological risk assessment of heavy metals in sediments of Nador lagoon, Morocco. Ecological Indicators, 48:616-626, 2015.

[4] N. Khajehzadeh and T.K. Kauppinen. Fast mineral identification using elemental LIBS technique. IFAC-PapersOnLine, 48(17):119-124, 2015.

[5] M. Bonta, J.J. Gonzalez, C.D. Quarles, R.E. Russo, B. Hegedus, and A. Limbeck. Elemental mapping of biological samples by the combined use of LIBS and LA-ICP-MS. Journal of Analytical Atomic Spectrometry, 31(1):252-258, 2016.

[6] L. Radziemski, D.A. Cremers, K. Benelli, C. Khoo, and R.D. Harris. Use of the vacuum ultraviolet spectral region for laser-induced breakdown spectroscopy-based martian geology and exploration. Spectrochimica Acta Part B: Atomic Spectroscopy, 60(2):237-248, 2005.

[7] C. Fabre, M.-C. Boiron, J. Dubessy, M. Cathelineau, and D.A. Banks. Palaeofluid chemistry of a single fluid event: a bulk and in-situ multitechnique analysis (LIBS, Raman Spectroscopy) of an Alpine fluid (Mont-Blanc). Chemical Geology, 182(2):249-264, 2002.

[8] F.C. DeLucia, A.C. Samuels, R.S. Harmon, R.A. Walters, K.L. McNesby, A. LaPointe, R.J. Winkel, and A.W. Miziolek. Laser-induced breakdown spectroscopy (LIBS): a promising versatile chemical sensor technology for hazardous material detection. IEEE Sensors Journal, 5(4):681-689, 2005.

[9] R.S. Harmon, F.C. DeLucia, C.E. McManus, N.J. McMillan, T.F. Jenkins, M.E. Walsh, and A. Miziolek. Laser-induced breakdown 
spectroscopy-an emerging chemical sensor technology for real-time fieldportable, geochemical, mineralogical, and environmental applications. Applied Geochemistry, 21(5):730-747, 2006.

[10] R.S. Harmon, F.C. De Lucia, A.W. Miziolek, K.L. McNesby, R.A. Walters, and P.D. French. Laser-induced breakdown spectroscopy (LIBS)an emerging field-portable sensor technology for real-time, in-situ geochemical and environmental analysis. Geochemistry: Exploration, Environment, Analysis, 5(1):21-28, 2005.

[11] D.W. Hahn and N. Omenetto. Laser-induced breakdown spectroscopy (LIBS), part II: review of instrumental and methodological approaches to material analysis and applications to different fields. Applied Spectroscopy, 66(4):347-419, 2012.

[12] J. Kaiser, K. Novotnỳ, M.Z. Martin, A. Hrdlička, R. Malina, M. Hartl, V. Adam, and R. Kizek. Trace elemental analysis by laser-induced breakdown spectroscopy - biological applications. Surface Science Reports, 67(11):233-243, 2012.

[13] F.J. Fortes, S. Guirado, A. Metzinger, and J.J. Laserna. A study of underwater stand-off laser-induced breakdown spectroscopy for chemical analysis of objects in the deep ocean. Journal of Analytical Atomic Spectrometry, 30(5):1050-1056, 2015.

[14] A. Matsumoto, A. Tamura, K. Fukami, Y.H. Ogata, and T. Sakka. Single-pulse underwater laser-induced breakdown spectroscopy with nongated detection scheme. Analytical Chemistry, 85(8):3807-3811, 2013.

[15] T. Takahashi, T. Blair, K. Ohki, T. Sakka, and K. Suzuki. Investigation of long-pulse laser-induced breakdown spectroscopy for analysis of the composition of rock and sediment samples submerged in seawater. In Oceans-San Diego, 2013, pages 1-6. IEEE, 2013.

[16] A.P.M. Michel, M. Lawrence-Snyder, S.M. Angel, and A.D. Chave. Laser-induced breakdown spectroscopy of bulk aqueous solutions at oceanic pressures: evaluation of key measurement parameters. Applied Optics, 46(13):2507-2515, 2007. 
[17] M. Lawrence-Snyder, J. Scaffidi, S.M. Angel, A.P.M. Michel, and A.D. Chave. Sequential-pulse laser-induced breakdown spectroscopy of highpressure bulk aqueous solutions. Applied Spectroscopy, 61(2):171-176, 2007.

[18] A.P.M. Michel and A.D. Chave. Single pulse laser-induced breakdown spectroscopy of bulk aqueous solutions at oceanic pressures: interrelationship of gate delay and pulse energy. Applied Optics, 47(31):G122G130, 2008.

[19] A.P.M. Michel and A.D. Chave. Double pulse laser-induced breakdown spectroscopy of bulk aqueous solutions at oceanic pressures: interrelationship of gate delay, pulse energies, interpulse delay, and pressure. Applied Optics, 47(31):G131-G143, 2008.

[20] S. Guirado, F.J. Fortes, V. Lazic, and J.J. Laserna. Chemical analysis of archeological materials in submarine environments using laser-induced breakdown spectroscopy. on-site trials in the Mediterranean Sea. Spectrochimica Acta Part B: Atomic Spectroscopy, 74:137-143, 2012.

[21] T. Takahashi, B. Thornton, K. Ohki, and T. Sakka. Calibration-free analysis of immersed brass alloys using long-ns-duration pulse laserinduced breakdown spectroscopy with and without correction for nonstoichiometric ablation. Spectrochimica Acta Part B: Atomic Spectroscopy, 111:8-14, 2015.

[22] F. Capitelli, F. Colao, M.R. Provenzano, R. Fantoni, G. Brunetti, and N. Senesi. Determination of heavy metals in soils by laser induced breakdown spectroscopy. Geoderma, 106(1):45-62, 2002.

[23] B. Bousquet, G. Travaillé, A. Ismaël, L. Canioni, K. Michel-Le Pierrès, E. Brasseur, S. Roy, I. Le Hecho, M. Larregieu, S Tellier, and M. PotinGautier. Development of a mobile system based on laser-induced breakdown spectroscopy and dedicated to in situ analysis of polluted soils. Spectrochimica Acta Part B: Atomic Spectroscopy, 63(10):1085-1090, 2008.

[24] R. Barbini, F. Colao, R. Fantoni, A. Palucci, and F. Capitelli. Application of laser-induced breakdown spectroscopy to the analysis of metals in soils. Applied Physics A, 69(1):S175-S178, 1999. 
[25] G.S. Senesi, M. Dell'Aglio, R. Gaudiuso, A. De Giacomo, C. Zaccone, O. De Pascale, T.M. Miano, and M. Capitelli. Heavy metal concentrations in soils as determined by laser-induced breakdown spectroscopy (LIBS), with special emphasis on chromium. Environmental Research, 109(4):413-420, 2009.

[26] W.T.Y. Mohamed and A. Askar. Study of the matrix effect on the plasma characterization of heavy elements in soil sediments using LIBS with a portable echelle spectrometer. Progress in Physics, page 46, 2007.

[27] M.E. Essington, G.V. Melnichenko, M.A. Stewart, and R.A. Hull. Soil metals analysis using laser-induced breakdown spectroscopy (LIBS). Soil Science Society of America Journal, 73(5):1469-1478, 2009.

[28] M. Barbafieri, R. Pini, A. Ciucci, and E. Tassi. Field assessment of Pb in contaminated soils and in leaf mustard (Brassica juncea): the LIBS technique. Chemistry and Ecology, 27(S1):161-169, 2011.

[29] B. Thornton, T. Takahashi, T. Ura, and T. Sakka. Cavity formation and material ablation for single-pulse laser-ablated solids immersed in water at high pressure. Applied Physics Express, 5(10):102402, 2012.

[30] R. Barbini, F. Colao, R. Fantoni, V. Lazic, A. Palucci, F. Capitelli, and H.J.L. Van der Steen. Laser induced breakdown spectroscopy for semi-quantitative elemental analysis in soils and marine sediments. In Proceedings of EARSeL-SIG-Workshop LIDAR, volume 1, pages 122 129, 2000.

[31] R. Barbini, F. Colao, V. Lazic, R. Fantoni, A. Palucci, and M. Angelone. On board LIBS analysis of marine sediments collected during the XVI Italian campaign in Antarctica. Spectrochimica Acta Part B: Atomic Spectroscopy, 57(7):1203-1218, 2002.

[32] A. De Giacomo, M. Dell'Aglio, F. Colao, and R. Fantoni. Double pulse laser produced plasma on metallic target in seawater: basic aspects and analytical approach. Spectrochimica Acta Part B: Atomic Spectroscopy, 59(9):1431-1438, 2004.

[33] B. Thornton, T. Takahashi, T. Sato, T. Sakka, A. Tamura, A. Matsumoto, T. Nozaki, T. Ohki, and K. Ohki. Development of a deep-sea 
laser-induced breakdown spectrometer for in situ multi-element chemical analysis. Deep Sea Research Part I: Oceanographic Research Papers, 95:20-36, 2015.

[34] B. Thornton, T. Sakka, T. Takahashi, A. Tamura, A. Matsumoto, and T. Ura. Laser-induced breakdown spectroscopy for in situ chemical analysis at sea. In Underwater Technology Symposium (UT), 2013 IEEE International, pages 1-7. IEEE, 2013.

[35] B. Thornton, T. Masamura, T. Takahashi, T. Ura, K. Ohki, and T. Sakka. Development and field testing of laser-induced breakdown spectroscopy for in situ multi-element analysis at sea. In Oceans, 2012, pages 1-6. IEEE, 2012.

[36] R. Payling and P. Larkins. Optical Emission Lines of the Elements. John Wiley and Sons, 2000.

[37] R. Noll, H. Bette, A. Brysch, M. Kraushaar, I. Mönch, L. Peter, and V. Sturm. Laser-induced breakdown spectrometry-applications for production control and quality assurance in the steel industry. Spectrochimica Acta Part B: Atomic Spectroscopy, 56(6):637-649, 2001.

[38] N.E. Widjonarko, J.D. Perkins, J.E. Leisch, P.A. Parilla, C.J. Curtis, D.S. Ginley, and J.J. Berry. Stoichiometric analysis of compositionally graded combinatorial amorphous thin film oxides using laserinduced breakdown spectroscopy. Review of Scientific Instruments, 81(7):073103, 2010.

[39] A.P.M. Michel and A.D. Chave. Analysis of laser-induced breakdown spectroscopy spectra: the case for extreme value statistics. Spectrochimica Acta Part B: Atomic Spectroscopy, 62(12):1370-1378, 2007.

[40] D.A. Cremers and A.K. Knight. Laser-Induced Breakdown Spectroscopy. Wiley Online Library, 2006.

[41] D.M. Díaz Pace, C.A. D’Angelo, D. Bertuccelli, and G. Bertuccelli. Analysis of heavy metals in liquids using laser induced breakdown spectroscopy by liquid-to-solid matrix conversion. Spectrochimica Acta Part B: Atomic Spectroscopy, 61(8):929-933, 2006. 
[42] W.G. Nelson and B.J. Bergen. The New Bedford Harbor Superfund site long-term monitoring program (1993-2009). Environmental monitoring and assessment, 184(12):7531-7550, 2012. 

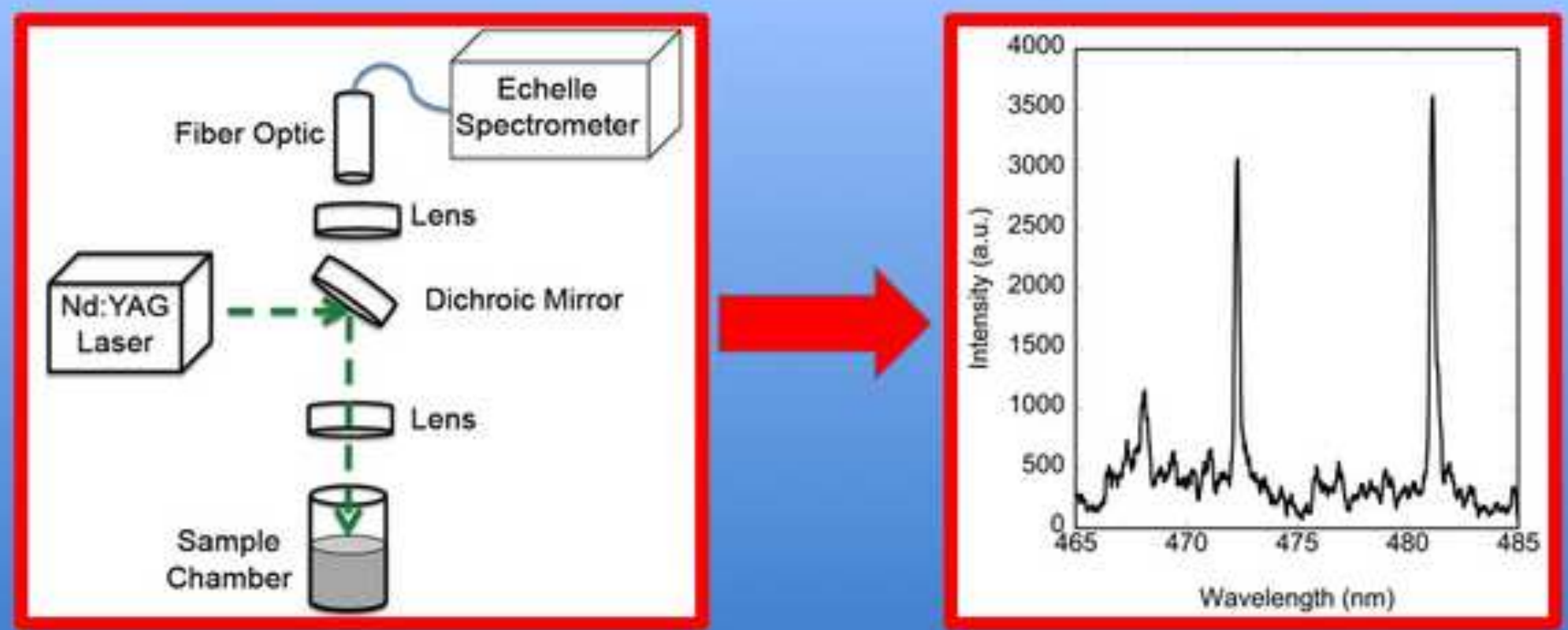